OPEN ACCESS

Edited by:

Paul Jurasz,

University of Alberta, Canada

Reviewed by:

Eric Boilard,

Laval University, Canada

Cécile Oury

University of Liège, Belgium

*Correspondence:

John Hwa

john.hwa@yale.edu

Specialty section:

This article was submitted to Atherosclerosis and Vascular

Medicine,

a section of the journa

Frontiers in Cardiovascular Medicine

Received: 03 September 2019 Accepted: 08 October 2019 Published: 29 October 2019

Citation:

Melchinger $H$, Jain $K$, Tyagi $T$ and Hwa J (2019) Role of Platelet

Mitochondria: Life in a Nucleus-Free

Zone. Front. Cardiovasc. Med. 6:153.

doi: 10.3389/fCvm.2019.00153

\section{Role of Platelet Mitochondria: Life in a Nucleus-Free Zone}

\author{
Hannah Melchinger, Kanika Jain, Tarun Tyagi and John Hwa* \\ Department of Internal Medicine, Yale Cardiovascular Research Center, Yale School of Medicine, New Haven, CT, \\ United States
}

Platelets are abundant, small, anucleate circulating cells, serving many emerging pathophysiological roles beyond hemostasis; including active critical roles in thrombosis, injury response, and immunoregulation. In the absence of genomic DNA transcriptional regulation (no nucleus), platelets require strategic prepackaging of all the needed RNA and organelles from megakaryocytes, to sense stress (e.g., hyperglycemia), to protect themselves from stress (e.g., mitophagy), and to communicate a stress response to other cells (e.g., granule and microparticle release). Distinct from avian thrombocytes that have a nucleus, the absence of a nucleus allows the mammalian platelet to maintain its small size, permits morphological flexibility, and may improve speed and efficiency of protein expression in response to stress. In the absence of a nucleus, platelet lifespan of 7-10 days, is largely determined by the mitochondria. The packaging of 5-8 mitochondria is critical in aerobic respiration and yielding metabolic substrates needed for function and survival. Mitochondria damage or dysfunction, as observed with several disease processes, results in greatly attenuated platelet survival and increased risk for thrombovascular events. Here we provide insights into the emerging roles of platelets despite the lack of a nucleus, and the key role played by mitochondria in platelet function and survival both in health and disease.

Keywords: platelets, mitochondria, anucleate cells, metabolism, apoptosis

\section{PLATELET DISCOVERY AND ORIGINS}

Platelets are small $(2-4 \mu \mathrm{m})$, short-lived (7-10 days), anucleate circulating cells primarily responsible for the prevention of bleeding and the maintenance of hemostasis $(1,2)$. A healthy adult has a counts in the range of 150,000-450,000 platelets per microliter of blood, though these counts vary with age and health (3). Platelets were first identified by Schultze in 1865 (4), but its functions in hemostasis and thrombosis weren't elucidated until 1881 by Bizzozero $(5,6)$. In 1906, Wright established megakaryocytes (MKs) in the bone marrow to be the source of platelets (7), though recent studies have shown that mature megakaryocytes in the lungs can also release platelets into the pulmonary vasculature (8). MKs produce billions of platelets daily through fragmentation, in which small cytoplasmic pieces bud off the megakaryocyte to become platelets (9). During fragmentation, MKs undergo a series of elongations to form proplatelet shafts, or cytoplasmic extensions which serve as assembly lines for platelet formation (10). Platelet-sized swellings then form along the shaft (11); as these platelets develop, they are loaded with the necessary organelles and granules from the MK parent (9). Platelets are equipped with mitochondria, a cytoskeleton, 
and a dense tubular system (DTS) (3, 12). Additionally, platelets contain secretory organelles categorized as alpha, dense, and lysosomal granules, which are transported and discharged by a surface-connected open canalicular system (OCS) (13). Dense granules generally contain small molecules such as ADP or serotonin, whereas alpha granules contain hemostatic factors such as fibrinogen, as well as other growth factors and cytokines (14). Upon complete generation, platelets are released from the bone marrow into circulation, where they live for the next 7-10 days (15). Historically disregarded as "cellular dust" (16), platelets have only recently emerged as having more diverse homeostatic processes including wound healing, angiogenesis, immunoregulation, and inflammatory response all key components to a stress response $(2,17-19)$.

\section{PLATELET FUNCTION BEYOND HEMOSTASIS (FIGURE 1)}

Platelets are primarily responsible for the maintenance of normal hemostasis by the prevention of hemorrhage during vascular injury (20). Hemostasis is achieved by a careful balance of platelet interactions with vascular components, cytokine mediators, fibrinolytic agents, and plasma coagulation mechanisms (21). They assist in initiating a vascular response leading to vasoconstriction, and formation of a hemostatic plug (through adhesion, activation, and aggregation). The blood coagulation cascade is then initiated with expansion of the thrombus and massive release of platelet contents (22). The released factors then also assist in promoting tissue repair and resolving the repair process (23). The role of platelets in thrombosis is essential, and increasingly becoming well-understood. Given the complex content within platelets, researchers have recently begun to investigate platelet function beyond coagulation, and have implicated platelets in several processes including immunoregulation, infection, inflammation, and the pathogenesis of a growing list of diseases (neurodegenerative diseases, cardiovascular disease and cancer) (24-26). In the absence of a nucleus, the role of the platelet mitochondria in these processes has become a focus of intense studies, including how platelet dysfunction is associated with, contribute to, is affected by the disease pathologies (25).

\section{PLATELETS: A NUCLEUS-FREE ZONE}

Notably, mammalian platelets do not contain a nucleus (27). Interestingly, non-mammalian vertebrates have nucleated thrombocytes that have limited responses, to thrombin but not to ADP, serotonin or epinephrine $(28,29)$. As described (9), upon fragmentation, mature mammalian MKs segregate into anucleate platelets; thus, platelets are not endowed with the genomic genetic material generally considered a requirement for complex cellular function (16). Nuclear material (genomic DNA) generally provides functional autonomy; any needed protein can be transcribed from the genomic road map provided in the nucleus (19). However, the presence of a nucleus in platelets may hinder many of the important roles played by the platelet, at the expense of functional autonomy. To fulfill the many emerging functions, platelets need to be small (able to circulate in small vessels), flexible, highly efficient (produces proteins rapidly and efficiently) and highly sensitive (responds to stressors rapidly).

A human cell nucleus on average is much larger than a platelet (nucleus $\sim 6 \mu \mathrm{m}$ in diameter) (30), dictated by DNA content ( 3 billion base pairs in humans), and cytoplasmic factors (31). The presence of a nucleus even if small and compact, would greatly enhance a platelet's size thus reducing its ability to travel through small vessels and spaces. In addition to small size, platelets need to be flexible, capable of modulating their internal space to undergo extreme morphological changes (19), again allowing platelets to travel through even the smallest vessels in the circulatory system and enter tissues when needed. Further, this enhanced flexibility allows the platelet OCS to fill internal vacancies during activation to increase surface area available for interaction with blood plasma $(19,32)$. The presence of a nucleus in avian thrombocytes (nucleated platelets) makes them larger than mammalian platelets, causes them to spread less efficiently on collagen, and express much lower levels of the $\alpha_{2 b} \beta_{3}$ integrin required for aggregate formation (28). Similarly, the lack of a nucleus within the red blood cells (RBC), allows them to maintain their distinct bi-concave shape; but additionally, removes the need to maintain nuclear function and genome, allowing the $\mathrm{RBC}$ to focus on producing and maintaining hemoglobin. Platelets, like RBCs, do not need to regulate the health of a large complex nucleus, with its transcriptional machinery and chromosomes. Platelets can thus focus on what is needed for their roles in hemostasis and homeostasis with prepackaged, carefully selected RNA and translational machinery (without requiring transcriptional regulation of complex genomic DNA) $(33,34)$. Each platelet is equipped with an abundance of needed genetic information, and processing machinery required for a highly efficient rapid response (35), within minutes (required for hemostasis), rather than hours or days. Thus, based upon the literature and the lower efficiency of nucleated avian thrombocytes, we believe that the lack of a nucleus allows for improved platelet functional efficiency. More studies are required to support this notion. Interestingly, in the absence of a nuclear source of RNA, platelets are capable of taking up RNA material from external sources through microvesicles (MVs) (36). RNAs can also be donated from platelets to other cells through microvesicle mediated intercellular crosstalk (37-39). The microRNAs within these MVs have proven to be increasingly relevant to understanding the role of platelets in thrombosis, immune response, and various diseases. Not only miRNA but transcription factors and mitochondria are conveyed to such cells as neutrophils, mediated by 12-lipoxygenase and phospholipase A2-IIA (40). Thus, platelets have proven to be "intelligent" even in the absence of a nucleus: a platelet's ability to interact with their environment and efficiently respond to the needs of that environment, has marked them as far more complex than previously thought (41). 


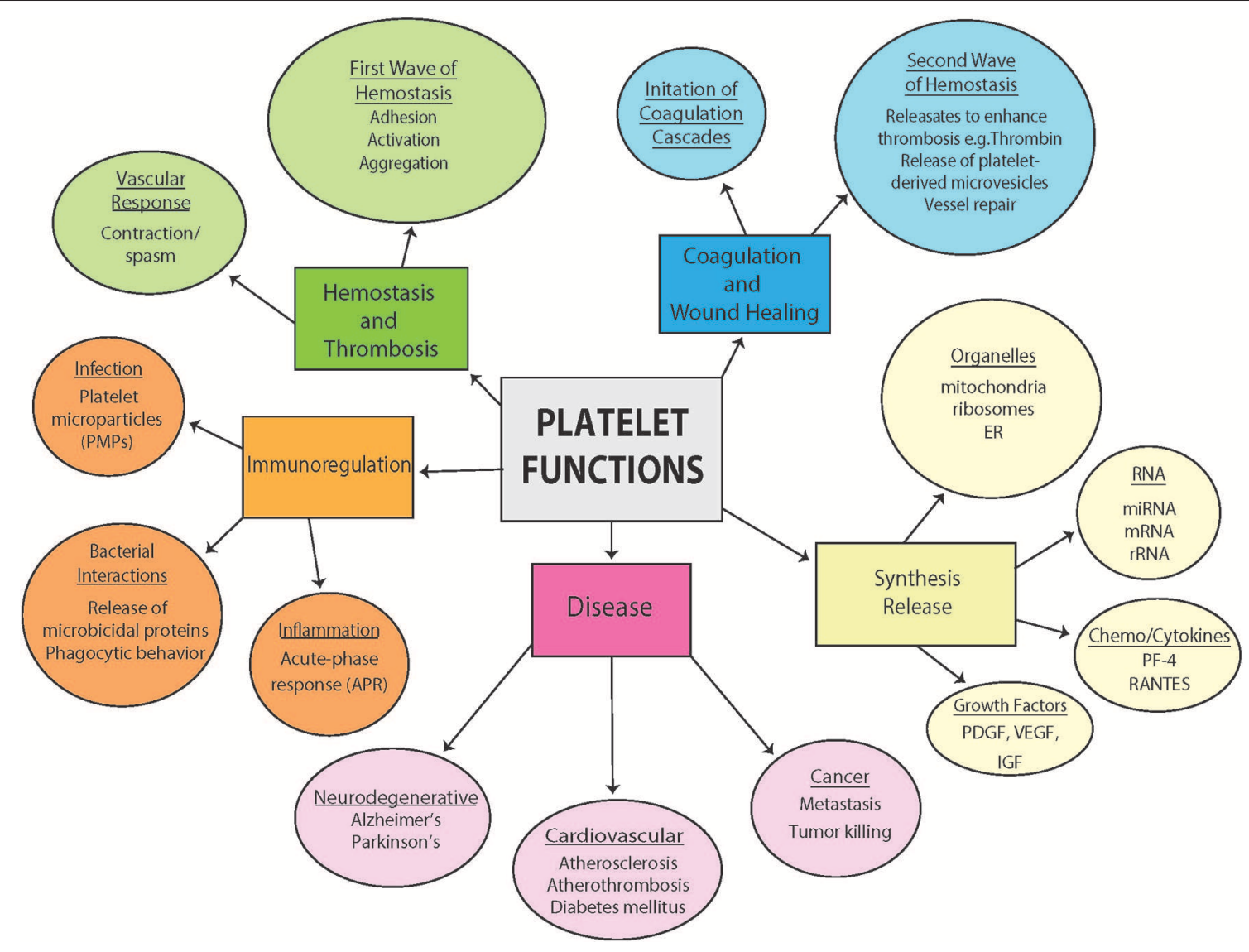

FIGURE 1 | Diversity of platelet function. Highlighted are some of the diverse pathophysiological functions of platelets both in health and disease from hemostasis and thrombosis to contributions to disease. Included are also a section outlining diverse synthesis and release of platelets and important involvement in immunoregulation.

\section{PLATELET MITOCHONDRIA ARE KEY TO FUNCTION AND SURVIVAL OF PLATELETS (FIGURE 2)}

To maintain the ability to rapidly respond to stressors or blood vessel damage (thrombosis), a highly efficient source of energy and metabolites are needed to orchestrate the response. Distinct from RBCs that are also devoid of mitochondria, platelets are equipped with mitochondria (42). Interestingly, mitochondria have a number of features in common with a nucleus, both contain DNA, both are surrounded by a double plasma membrane, and both can divide during the cell cycle (30). However, the role of the mitochondria, referred as the "powerhouse of the cell," is quite different, playing essential roles in energy production and metabolism (43). The mitochondria is home to key energetic processes such as the tricarboxylic acid (TCA) cycle and oxidative phosphorylation (OXPHOS), both of which are involved in the production of adenosine triphosphate (ATP) (44). However, studies have implicated mitochondria in many processes beyond energy production, such as the generation of reactive oxygen species (ROS) (45), $\mathrm{Ca}^{2+}$ homeostasis (46), apoptosis regulation (47), and ER-stress response mechanisms (48). Mitochondrial health and dysfunction also appear to be involved in aging (49), as well as neurodegenerative diseases (e.g., Alzheimer's (50) and Parkinson's disease (51). Healthy platelets contain between 5 and 8 mitochondria, the majority of which must remain uncompromised for the platelet to maintain proper function. In healthy platelets, mitochondria has been demonstrated to serve a variety of purposes as described for nucleated cells, from metabolism, activation, ATP production to the regulation of cell processes and viability $(42,52)$.

In the absence of nuclear control, platelet health is largely determined by the health of their mitochondria (53). As is apparent in a number of diseases, an excess of damaged platelets can lead to premature apoptosis; therefore, it is essential to keep platelet mitochondria in good health (25). The turnover rate for mitochondria in various nucleated cells ranges from 9 to 24 days $(54,55)$. Considering, the lifespan of a platelet (7-10 days), the necessity of mitochondria for energy production, and the inability to consistently replenish nuclear encoded mitochondria proteins, the lifespan of the platelet mitochondria likely determines the platelet lifespan. A mitochondrial protein $\mathrm{Bcl}-\mathrm{xl}$, master regulator of mitochondrial apoptosis has been reported to determine platelet lifespan (56). Moreover, a recent study implicated TNF-alpha-driven megakaryocyte reprogramming 


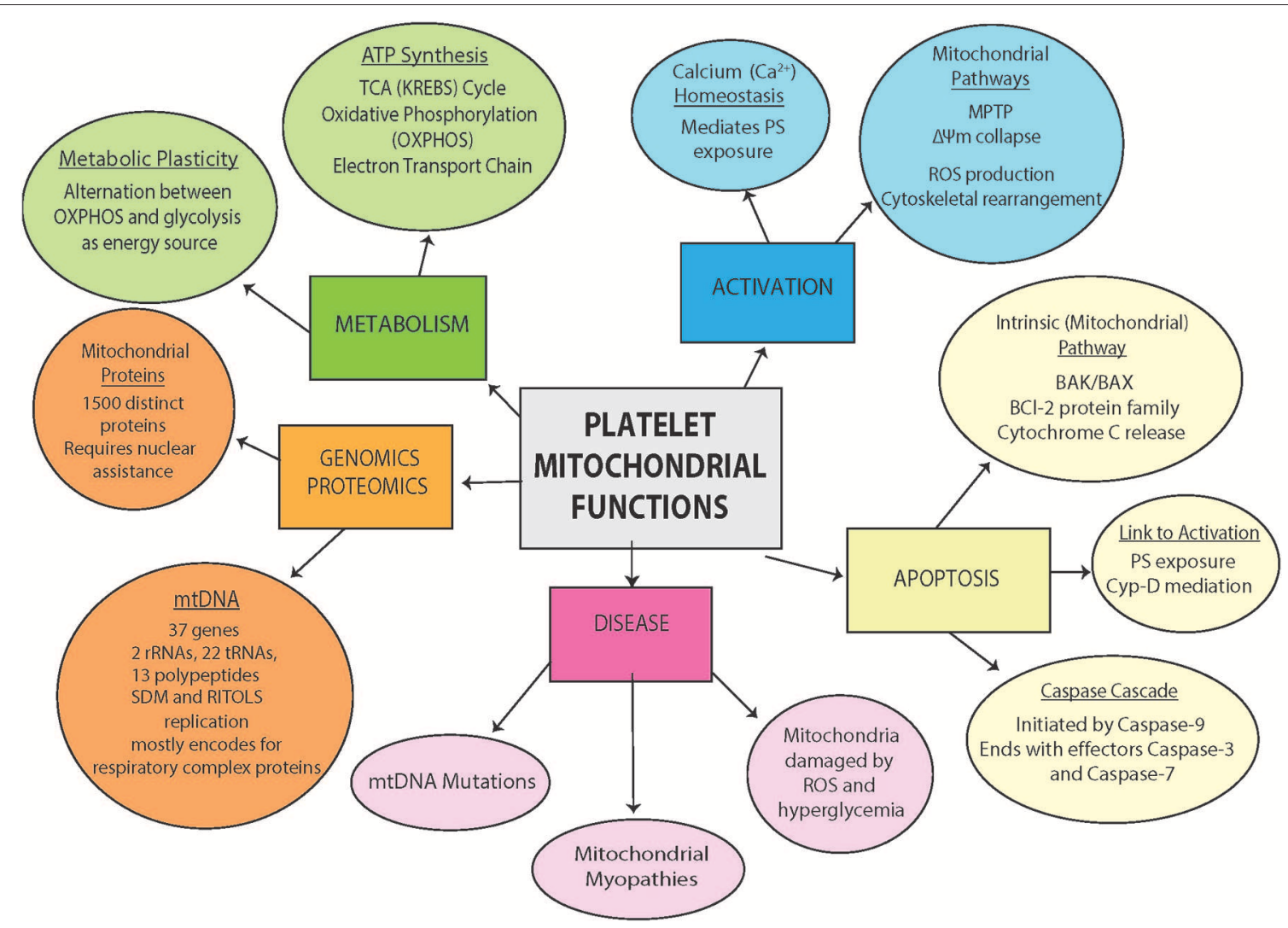

FIGURE 2 | Platelet mitochondrial Functions. Outlined are platelet mitochondria contents (genomics and proteomics), physiological function (metabolism), and involvement in pathology and disease (process of activation, apoptosis and disease involvement).

leading to increased mitochondrial mass and activity as being a major contributor to the observed hyperactivity and thrombosis associated with aging (57). Multiple factors affect mitochondrial health and some of the key components determining mitochondria function and lifespan, especially in context of the anucleate platelets, will now be discussed.

\section{Mitochondria DNA (mtDNA)}

A complete mitochondrial genome is needed for both proper mitochondrial as well as platelet function, and the prevention of a number of mitochondrial related diseases such as mitochondrial myopathies caused by mtDNA mutations (58). Mitochondria, along with chloroplasts in plants, are the only organelles besides the nucleus to contain genetic material (59). Human mitochondrial DNA (mtDNA) is double-stranded, circular, and relatively small: at $16.6 \mathrm{kbp}$, human mtDNA is comprised of 37 genes encoding two rRNAs, 22 tRNAs, and 13 polypeptides, all of which are components of the OXPHOS enzyme complexes (60). Similar to bacterial chromosomal DNA, mtDNA is organized, in multiple copies, in nucleoids within the mitochondria (61). Because they likely originated from prokaryotic ancestors, mitochondria are largely self-sufficient: they are able to maintain, transcribe and translate mtDNA internally and independently (62). Mitochondria have several modes of mtDNA replication which differ significantly from the nuclear mode of replication including the strand-displacement mode (SDM) (63, 64), ribonucleotide incorporated throughout the lagging strand replication (RITOLS) (65) and coupled leading-lagging strand synthesis (66). mtDNA copy number is considered an indirect measure of mitochondrial function (67) and its quantification in peripheral blood, majorly reflects the mtDNA copy number in leukocytes and platelets (68). The epigenetic regulation of platelet mtDNA is of particular importance with higher methylation of platelet mtDNA being a possible biomarker for cardiovascular disease (CVD) $(69,70)$.

\section{Mitochondrial Functions}

In addition to mtDNA, mitochondria are equipped with a complex array of proteins offering significant insights into mitochondrial activity (71). Mitochondria contain around 1,500 distinct proteins in mammals, compared to around 1,000 in yeast (72). Since the majority of the proteins encoded by mtDNA form components of the respiratory chain complexes, most mitochondrial proteins are encoded by the nucleus and imported into the mitochondria from the cytosol with the help of mitochondrial translocases (73). Each protein is coupled with a distinct import signal which guides it to the appropriate mitochondrial membrane, to which it is then inserted: outer membrane proteins are integrated by the TOM complex, whereas TIM23 is the presequence translocase responsible for 
inner membrane protein integration (74). The mechanism by which proteins are incorporated into the mitochondria is posttranslational: unlike ER-protein import, mitochondrial proteins are synthesized in the cytosol as precursor proteins before being translocated into a mitochondrion (75).

\section{Mitochondria and Energy Metabolism in the Platelets}

While most human nucleated cells contain hundreds, if not thousands, of active mitochondria, platelets generally contain only 5-8 mitochondria per cell (42). However, metabolically, platelets are quite active: for example, compared to resting mammalian muscle cells, platelets have much higher levels of ATP-turnover (69). This energy demand is met using a metabolic system which combines the efforts of glycolysis and mitochondrial OXPHOS. In platelets, glycolysis provides about $60 \%$ of cellular ATP, while OXPHOS provides the remaining 30$40 \%$ (25). Out of the platelet's total mitochondrial function, 50\% is dedicated to ATP production; the reserve energy is responsible for, among other activities, cellular response to oxidative stress (76). ATP is essential to proper platelet function: several key processes that occur within the platelet, such as the maintenance of calcium homeostasis, require a constant energy supply. Interestingly, platelets have been shown to have a metabolic flexibility that helps them meet this energy demand; activated platelets exhibit a glycolytic phenotype even as they preserve mitochondria function (77). This ability to utilize glycolysis or fatty acid catabolism instead of OXPHOS (mitochondrial ATP production) allows the platelet to adapt to different situations, such as hypoxia or the presence of mitochondrial inhibitory agents (78). Several studies have shown that platelet aggregation along with other metabolic activities are only fully interrupted when mitochondrial OXPHOS and glycolysis are inhibited simultaneously (79). Indeed, double knockout of GLUT1 and GLUT3 (major transporters of platelet glucose) leads to mitochondria reprograming, reduced thrombosis and reduced platelet activation along with thrombocytopenia (80). This suggests that this metabolic plasticity is the key to enabling platelets to meet their extraordinary energy demand with so few mitochondria.

\section{Mitochondria and Platelet Activation}

Platelets are activated during the adhesion events of primary homeostasis, and the initiation of the blood coagulation cascades (81). Until recently, it was assumed that the only role mitochondria played in this process was an energetic one (78). However, new studies have demonstrated the contributions of several mitochondrial functions in platelet activation such as the mitochondrial permeability transition (MPT) $(82,83)$, increased ROS generation (84-86), and collapse of mitochondrial membrane potential $\left(\Delta \Psi_{\mathrm{m}}\right)$. Platelet activation is mediated by several agonists: collagen, thrombin, and ADP have all been implicated in the regulation of hemostasis (87). The activity of these agonists is mediated by a common increase in intracellular calcium (88). Mitochondria do little to regulate platelet calcium levels (89), but a simultaneous increase in intramitochondrial calcium levels does mediate phosphatidylserine (PS) exposure, without affecting integrin activation and granule release (86).
Increased mitochondrial calcium levels also correlate with mitochondrial ROS imbalance and MPT pore activation (90). Strong platelet activation characterized by the drastic increase in mitochondrial and cytosolic calcium also seems to initiate the collapse of the mitochondrial membrane potential $\left(\Delta \Psi_{\mathrm{m}}\right)$ via a cyclophilin D (CypD)-dependent mechanism (56). Thus, this collapse, mediated by mitochondrial calcium, contributes to further ROS generation and the initiation of the PS exposure essential for platelet adhesion (85). Interestingly, these mitochondrial activation pathways also contribute to the platelet apoptosis framework $(84,91,92)$.

\section{Mitochondria and Apoptosis (Figure 3)}

Long associated only with nucleated cells, apoptosis is a mechanism of systematic cell deletion which can be induced or inhibited by both normal and abnormal stimuli (96). However, recent studies have identified apoptosis in the anucleate platelet $(96,97)$. Morphologically, platelet apoptosis is characterized by blebbing, platelet shrinkage, PS exposure, fragmentation into microparticles, and filopod formation (96). Apoptosis follows either an extrinsic or intrinsic pathway, the former stimulated by the activation of cell-surface death receptors, and the latter mediated by mitochondrial coordination of pro- and antiapoptotic members of the Bcl-2 family (98). The presence of Bcl-2 family proteins within platelets, along with the platelet PS exposure characteristic of apoptosis, suggests that platelets might primarily follow an intrinsic apoptotic pathway $(99,100)$. $\mathrm{Bcl}-\mathrm{x}_{\mathrm{L}}$, the key regulator of platelet survival, is responsible for inhibiting BAK and BAX, two pro-apoptotic proteins which serve to damage the mitochondria: studies in which either Bcl$\mathrm{x}_{\mathrm{L}}$ or $\mathrm{BAK} / \mathrm{BAX}$ were impaired saw interference with natural platelet lifespan $(98,101,102)$. Overexpression of Bcl-2 family pro-survival proteins can increase survival of platelets in the circulation (103). However, deletion of Bcl-2 in mice did not affect thrombopoiesis or platelet life span (104), supporting compensatory responses. When platelets come under stress or reach their natural end, the survival signal is overwhelmed and causes the activation of BAK and BAX, initiating the subsequent release of mitochondrial components such as cytochrome $c$ through pores in the mitochondrial membrane (105). The presence of cytochrome $c$ in the cytosol triggers the apoptotic caspase cascade, which begins with the initiator caspase- 9 and ends with the effectors caspase- 3 and caspase-7, which cleave hundreds of intracellular components and effectively destroy several essential cellular processes (106). Interestingly BCL2 family proteins are also involved in platelet formation with the anti-apoptotic family member BCL2L2 being involved in increasing megakaryocyte proplatelet formation in cultures of human cord blood (107).

\section{Mitophagy in Platelets/Mitochondrial Turnover in Platelets (Figure 3)}

Highlighting the importance of protecting platelet mitochondria in maintaining platelet health and lifespan, the protective process of induced mitophagy was recently described in platelets (95). This is distinct from basal platelet autophagy needed for an important role in platelet activation (108-110). Mitophagy can 


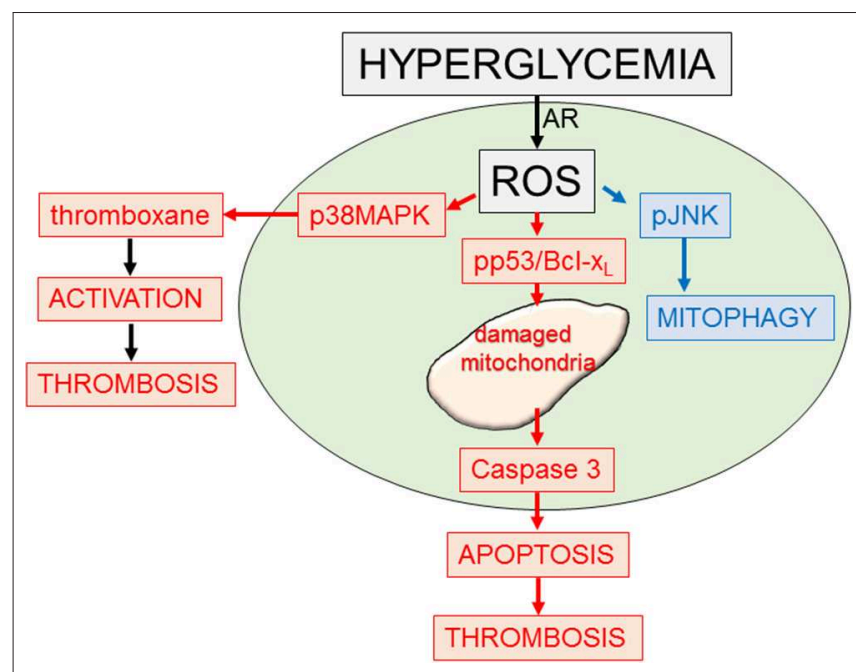

FIGURE 3 | Platelet response to hyperglycemia. Diagram outlining some of the signaling and functional responses to stress (hyperglycemia). Increased glucose (hyperglycemia) through the aldose reductase enzymic system can lead to enhanced reactive oxygen species (ROS). This can activate multiple pathways including p38MAPK, promoting platelet activation and thrombosis (93); phosphor-p53 and $\mathrm{Bcl}-\mathrm{xl}$, promoting mitochondrial damage, apoptosis, and thrombosis (94); and a mitophagy rescue response, removing toxic damaged mitochondria (95).

be generated by Parkin-independent or -dependent pathways (111-115) The process in platelets is Parkin-dependent and protects the platelet from oxidative stress and mitochondrial mediated damage (95). In the absence of a nucleus the platelet requires prepacking of the highly ordered and complex process, from initial phagophore formation (nucleation) to subsequent expansion of the membrane by ubiquitin-like conjugating systems, microtubule-associated protein 1 light chain 3 (LC3), and the autophagy protein system (ATGs), ultimately the phagophore completely surrounding its target, followed by fusion with a lysosome, leading to content degradation by lysosomal enzymes (116-118). The energy required to sort and prepackage the mRNA components for this process in anticipation of mitochondria stress/damage suggests an essential role for platelet mitochondria in health and disease. Platelet mitophagy removes toxic damaged mitochondria (as in diabetes mellitus) preventing platelet apoptosis $(95,119)$. If platelet mitophagy is impaired, increased platelet apoptosis can contribute to enhanced thrombosis (95).

\section{PLATELET MITOCHONDRIA IN DISEASE}

Because mitochondria play such an integral role in platelet metabolism, activation, and apoptosis, it is no surprise that mitochondrial dysfunction contribute to dysfunctional platelet activity and apoptosis in several diseases, most notably Alzheimer's and Parkinson's (120), cardiovascular disease (CVD) (121), diabetes mellitus (122), and sepsis (123). Apoptotic platelets induce clotting 50-100 times faster than normal platelets, because phosphatidylserine on the platelet surface acts as a catalytic site for clotting enzyme assembly and thrombin generation $(124,125)$. Recent studies have therefore provided invaluable insight into the complex mitochondrial mechanisms that determine platelet function in relation to tissue homeostasis (126). Due to the decreased fidelity of PolyG during replication, the mutation rate of $\mathrm{mtDNA}$ is about 100 -fold higher than that of nuclear DNA (127). Additionally, the process of mitochondrial DNA segregation occurs randomly and with far less organization than in the nucleus, sometimes leaving daughter cells with similar, but not identical, copies of mtDNA (128). Combined, there is increased risk for mtDNA abnormalities and mutations that can have severe health consequences, hindering ATP generation and increasing oxidative stress (129). Mutations which impact mitochondrial functionality are also relevant in aging (130) and age-related diseases, such as diabetes mellitus (58), Parkinson's (51), and cardiovascular disease (69). Platelet mitochondrial DNA in the circulation may serve as biomarkers for disease (131-133).

Cardiovascular diseases (CVD) including atherosclerosis and thrombosis are the leading causes of death for patients with diabetes (134). Diabetes mellitus, characterized by acute and chronic hyperglycemia have been shown to increase mitochondrial ROS production in platelets leading to activation $(85,93,135)$. Platelets have also been identified as leading players in the development of atherosclerotic lesions, contributing, along with monocytes, to the inflammatory environment of atherosclerosis $(136,137)$. Type 2 diabetes results in alterations of platelet ATP production with an initial increase in platelet mitochondrial ATP content and platelet activity (93, 138), followed by platelet apoptosis and a decrease in ATP production, in the presence of severe persistent oxidative stress $(94,138,139)$. Antiplatelet therapies, as well as hyperglycemic control treatments, have become increasingly relevant for the regulation of the high levels of platelet reactivity observed in Type 2 diabetes $(140,141)$. Preserving platelet mitochondrial function may be an additional means of decreasing the risk of potentially fatal thrombotic events for diabetic patients (142). Platelets may also serve essential functions in immunoregulation (143-146). Alterations in the bioenergetics of platelet mitochondria have been observed in cases of sepsis (147), contributing to drastic, but impermanent, organ failure (148). Thrombocytopenia is associated with increased mortality in septic shock $(149,150)$. Recently, platelet mitochondria have also been reported to incite an inflammatory response upon activation through release of bioenergetically active mitochondria in free as well as encapsulated form (151). Interestingly, the alphaproteobacterium Rickettsia prowazekii may be an evolutionary ancestor of the mitochondria (152).

Both Parkinson's and Alzheimer's are severe neurodegenerative diseases that have been linked to platelets, mitochondrial dysfunction and platelet apoptosis (153, 154). Platelets, are considered to be structurally and functionally similar to neurons and have been shown to rich in key proteins associated with the neurons and brain (155-157). Indeed, after the brain, platelets contain the highest amounts of Amyloid precursor protein, synuclein and tau, and are major contributors to the circulating levels of these key proteins involved in 
neurodegenerative diseases (158). As in the other diseases profiled, Alzheimer's presents a compromised mitochondrial ETC; in particular, the activity of cytochrome c oxidase, an oxidative metabolic component of Complex IV, has been shown to be impaired (159). Platelet mitochondria in Alzheimer's have been observed as having increased levels of oxidative stress leading to mitochondrial damage and platelet apoptosis (160). Studies of mitochondrial function in Parkinson's disease have identified mutations or defects in Complex I-IV of the ETC, $\alpha$-synuclein, PARKIN, PINK1, DJ-1, and LRRK2 (139). A decrease in Complexes I and IV can develop quickly within the first year of Parkinson's $(161,162)$, and low levels of activity in platelet mitochondrial complexes I and II/III in early, untreated Parkinson's (163). Other key protein associations include, NADH CoQ reductase, key to Complex I dysfunction (154), coenzyme Q10, a key electron receptor in Complexes I and II of the mitochondrial ETC (164-166) and the neurotransmitterdegrading enzyme monoamine oxidase B (MAO) (167-169). Implicated in the pathogenesis of both Alzheimer's and aging in general, platelet MAO has been used as a peripheral biomarker for the onset of Alzheimer's and Parkinson's (170, 171). Also consistent with the association of oxidative stress induced mitochondrial damage and apoptosis with Parkinson's disease, levels of the oxidative protective protein methionine sulfoxide reductase type 2 (Msrb2) was recently shown to be reduced in platelets of Parkinson's disease patients leading to increased platelet apoptosis (119). Indeed, platelet mitochondria may serve as an important biomarker in PD. These neurodegenerative diseases once again demonstrate the essential nature of platelet mitochondria for survival as reduced function and damage either through genetic defects or environmental stress leads to apoptosis and premature platelet death.

With the importance of mitochondria in platelet function and the potential contributions of mitochondria dysfunction to aging $(49,130)$ and age-related diseases, such as diabetes mellitus (58,

\section{REFERENCES}

1. Holinstat M. Normal platelet function. Cancer Metas Rev. (2017) 36:1958. doi: 10.1007/s10555-017-9677-x

2. van der Meijden PEJ, Heemskerk JWM. Platelet biology and functions: new concepts and clinical perspectives. Nat Rev Cardiol. (2019) 16:16679. doi: 10.1038/s41569-018-0110-0

3. Ghoshal K, Bhattacharyya M. Overview of platelet physiology: its hemostatic and nonhemostatic role in disease pathogenesis. ScientificWorldJournal. (2014) 2014:781857. doi: 10.1155/2014/781857

4. Herter JM, Rossaint J, Zarbock A. Platelets in inflammation and immunity. J Thromb Haemost. (2014) 12:1764-75. doi: 10.1111/jth.12730

5. Hou Y, Carrim N, Wang Y, Gallant RC, Marshall A, Ni H. Platelets in hemostasis and thrombosis: novel mechanisms of fibrinogen-independent platelet aggregation and fibronectin-mediated protein wave of hemostasis. $J$ Biomed Res. (2015) 29:437-44. doi: 10.7555/JBR.29.20150121

6. Bizzozero G. Uber einen neuen Formbestandtiel des Blutes und dessen Rolle bei der Thrombose und Blutgrinnung. Virchows Arch. (1882) 90:261332. doi: 10.1007/BF01931360

7. Wright JH. The origin and nature of the blood plates. Boston Med Surg J. (1906) 154:643-5. doi: 10.1056/NEJM190606071542301

8. Lefrançais E, Ortiz-Muñoz G, Caudrillier A, Mallavia B, Liu F, Sayah DM, et al. The lung is a site of platelet biogenesis
93, 94), Parkinson's (51, 119), and cardiovascular disease (69), targeting platelet mitochondria may serve as adjunct therapies. Drugs targeting platelet mitochondria metabolism and apoptosis may help prevent pathological thrombosis and contributions to disease. The genomics and proteomics of the mitochondria (Figure 2) provide multiple potential targets as outlined in an excellent recent review by Fuentes et al. (172). However, selective targeting to platelets may require further coupling to platelet targeting agents.

\section{CONCLUSION}

Mitochondria in nucleated cells have been well-described. While mitochondria functions are similar, its role becomes increasingly important in the nucleus-free zone of the platelet. As described in this review, not only are mitochondria involved in energy metabolism and ATP production in the platelets, they are also the central drivers of platelet activation and apoptosis; both events critical for platelet function and lifespan. The pathophysiological role played by platelet and their mitochondria in many systemic diseases remain under intense investigation. Therapies targeting platelet mitochondria may ultimately prove beneficial for such disease processes.

\section{AUTHOR CONTRIBUTIONS}

$\mathrm{HM}$ and JH conceived the paper. HM wrote the first draft. KJ, TT, and $\mathrm{JH}$ extensively reviewed and edited the paper.

\section{FUNDING}

This manuscript was supported by grants from NIH NHLBI, grants HL115247, HL122815 and a Pilot Grant from the Claude D. Pepper Older Americans Independence Center at Yale School of Medicine (P30AG021342). and a reservoir for haematopoietic progenitors. Nature. (2017) 544:105-9. doi: 10.1038/nature21706

9. Patel SR, Hartwig JH, Italiano JE Jr. The biogenesis of platelets from megakaryocyte proplatelets. J Clin Invest. (2005) 115:334854. doi: 10.1172/JCI26891

10. Thon JN, Montalvo A, Patel-Hett S, Devine MT, Richardson JL, Ehrlicher A, et al. Cytoskeletal mechanics of proplatelet maturation and platelet release. J Cell Biol. (2010) 191:861. doi: 10.1083/jcb.201006102

11. Machlus KR, Italiano JE. The incredible journey: from megakaryocyte development to platelet formation. J Cell Biol. (2013) 201:785. doi: 10.1083/jcb.201304054

12. Ebbeling L, Robertson C, McNicol A, Gerrard JM. Rapid ultrastructural changes in the dense tubular system following platelet activation. Blood. (1992) 80:718. doi: 10.1182/blood.V80.3.718.bloodjournal803718

13. Escolar GG, White J. The platelet open canalicular system: a final common pathway. Blood Cells. (1991) 17:467-85.

14. Youssefian T, Massé JM, Rendu F, Guichard J, Cramer EM. Platelet and megakaryocyte dense granules contain glycoproteins Ib and IIb-IIIa. Blood. (1997) 89:4047. doi: 10.1182/blood.V89.11.4047

15. Lebois M, Josefsson EC. Regulation of platelet lifespan by apoptosis. Platelets. (2016) 27:497-504. doi: 10.3109/09537104.2016.1161739

16. Garraud O, Cognasse F. Are Platelets Cells? And if Yes, are They Immune Cells? Front Immunol. (2015) 6:70. doi: 10.3389/fimmu.2015.00070 
17. Kapur R, Zufferey A, Boilard E, Semple JW. Nouvelle cuisine: platelets served with inflammation. J Immunol. (2015) 194:557987. doi: 10.4049/jimmunol.1500259

18. Vieira-de-Abreu, Campbell RA, Weyrich AS, Zimmerman GA. Platelets: versatile effector cells in hemostasis, inflammation, and the immune continuum. Semin Immunopathol. (2012) 34:5-30. doi: 10.1007/s00281-011-0286-4

19. Li JL, Zarbock A, Hidalgo A. Platelets as autonomous drones for hemostatic and immune surveillance. J Exp Med. (2017) 214:2193. doi: 10.1084/jem.20170879

20. Walsh PN. Platelet coagulant activities and hemostasis: a hypothesis. Blood. (1974) 43:597. doi: 10.1182/blood.V43.4.597.597

21. Periayah MH, Halim AS, Mat Saad AZ. Mechanism action of platelets and crucial blood coagulation pathways in hemostasis. Int J Hematol Oncol Stem Cell Res. (2017) 11:319-27.

22. Johnson SA, Van Horn DL, Pederson HJ, Marr J. The function of platelets. Transfusion. (1966) 6:3-17. doi: 10.1111/j.1537-2995.1966.tb04686.x

23. Zeng Z, Xia L, Fan X, Ostriker AC, Yarovinsky T, Su M, et al. Platelet-derived miR-223 promotes a phenotypic switch in arterial injury repair. J Clin Invest. (2019) 129:1372-86. doi: 10.1172/JCI124508

24. Ferroni P, Vazzana N, Riondino S, Cuccurullo C, Guadagni F, Davì G. Platelet function in health and disease, from molecular mechanisms, redox considerations to novel therapeutic opportunities. Antioxidants Redox Signal. (2012) 17:1447-85. doi: 10.1089/ars.2011.4324

25. Wang L, Wu Q, Fan Z, Xie R, Wang Z, Lu Y. Platelet mitochondrial dysfunction and the correlation with human diseases. Biochem Soc Trans. (2017) 45:1213. doi: 10.1042/BST20170291

26. Chae WJ, Ehrlich AK, Chan PY, Teixeira AM, Henegariu O, Hao L, et al. The Wnt Antagonist dickkopf-1 promotes pathological type 2 cell-mediated inflammation. Immunity. (2016) 44:246-58. doi: 10.1016/j.immuni.2016.01.008

27. Schwartz RS, Conley CL. Blood. In: Encyclopedia Britannica. Encyclopedia Britannica, Inc. Available online at: https://www.britannica.com/science/ blood-biochemistry

28. Schmaier AA, Stalker TJ, Runge JJ, Lee D, Nagaswami C, Mericko P, et al. Occlusive thrombi arise in mammals but not birds in response to arterial injury: evolutionary insight into human cardiovascular disease. Blood. (2011) 118:3661-9. doi: 10.1182/blood-2011-02-338244

29. Belamarich FA, Shepro D, Kien M. ADP is not involved in thrombin-induced aggregation of thrombocytes of a non-mammalian vertebrate. Nature. (1968) 220:509-10. doi: 10.1038/220509a0

30. Alberts B. Molecular Biology of the Cell. New York, NY: Garland Science, Taylor and Francis Group (2015).

31. Webster M, Witkin KL, Cohen-Fix O. Sizing up the nucleus: nuclear shape, size and nuclear-envelope assembly. J Cell Sci. (2009) 122:147786. doi: $10.1242 /$ jcs. 037333

32. White JG, Clawson CC. The surface-connected canalicular system of blood platelets-a fenestrated membrane system. Am J Pathol. (1980) 101:353-64.

33. Weyrich AS, Lindemann S, Tolley ND, Kraiss LW, Dixon DA, Mahoney TM, et al. Change in protein phenotype without a nucleus: translational control in platelets. Semin Thromb Hemost. (2004) 30:491-8. doi: 10.1055/s-2004-833484

34. Rowley JW, Schwertz H, Weyrich AS. Platelet mRNA: the meaning behind the message. Curr Opin Hematol. (2012) 19:385-91. doi: 10.1097/MOH.0b013e328357010e

35. Weyrich AS, Schwertz H, Kraiss LW, Zimmerman GA. Protein synthesis by platelets: historical and new perspectives. J Thromb Haemost. (2009) 7:241-6. doi: 10.1111/j.1538-7836.2008.03211.x

36. Nilsson RJA, Balaj L, Hulleman E, van Rijn S, Pegtel DM, Walraven M, et al. Blood platelets contain tumor-derived RNA biomarkers. Blood. (2011) 118:3680. doi: 10.1182/blood-2011-03-344408

37. Xia L, Zeng Z, Tang WH. The role of platelet microparticle associated microRNAs in cellular crosstalk. Front Cardiovasc Med. (2018) 5:29. doi: 10.3389/fcrm.2018.00029

38. Clancy L, Freedman JE. Blood-derived extracellular RNA and platelet pathobiology: adding pieces to a complex circulating puzzle. Circ Res. (2016) 118:374-6. doi: 10.1161/CIRCRESAHA.115.308190
39. Risitano A, Beaulieu LM, Vitseva O, Freedman JE. Platelets and plateletlike particles mediate intercellular RNA transfer. Blood. (2012) 119:628895. doi: 10.1182/blood-2011-12-396440

40. Duchez AC, Boudreau LH, Naika GS, Bollinger J, Belleannee C, Cloutier N, et al. Platelet microparticles are internalized in neutrophils via the concerted activity of 12-lipoxygenase and secreted phospholipase A2-IIA. Proc Natl Acad Sci USA. (2015) 112:E3564-73. doi: 10.1073/pnas.1507905112

41. Neelamegham S. The computing platelet: integrating environmental cues. Blood. (2012) 120:3. doi: 10.1182/blood-2012-05-426007

42. Hayashi T, Tanaka S, Hori Y, Hirayama F, Sato EF, Inoue M. Role of mitochondria in the maintenance of platelet function during in vitro storage. Transf Med. (2011) 21:166-74. doi: 10.1111/j.1365-3148.2010.01065.x

43. Kühlbrandt W/ Structure and function of mitochondrial membrane protein complexes. BMC Biol. (2015) 13:89. doi: 10.1186/s12915-015-0201-x

44. Bonora M, Patergnani S, Rimessi A, De Marchi E, Suski JM, Bononi A, et al. ATP synthesis and storage. Purin Signal. (2012) 8:34357. doi: 10.1007/s11302-012-9305-8

45. Hekimi S, Wang Y, Noë A. Mitochondrial ROS and the effectors of the intrinsic apoptotic pathway in aging cells: the discerning killers! Front Genet. (2016) 7:161. doi: 10.3389/fgene.2016.00161

46. Sarasija S, Norman KR. A $\gamma$-Secretase independent role for presenilin in calcium homeostasis impacts mitochondrial function and morphology in Caenorhabditis elegans. Genetics. (2015) 201:1453-66. doi: 10.1534/genetics.115.182808

47. Wang C, Youle RJ. The role of mitochondria in apoptosis*. Ann Rev Genet. (2009) 43:95-118. doi: 10.1146/annurev-genet-102108-134850

48. H.-Kim E, Grant AR, Simic MS, Kohnz RA, Nomura DK, Durieux J, et al. Lipid biosynthesis coordinates a mitochondrial-to-cytosolic stress response. Cell. (2016) 166:1539-1552.e16. doi: 10.1016/j.cell.2016.08.027

49. Jain K, Tyagi T, Patell K, Xie Y, Kadado AJ, Lee SH, et al. Age associated non-linear regulation of redox homeostasis in the anucleate platelet: implications for CVD risk patients. EBioMedicine. (2019) 44:2840. doi: 10.1016/j.ebiom.2019.05.022

50. Swerdlow RH. Mitochondria and mitochondrial cascades in Alzheimer's Disease. J Alzheimer's Dis. (2018) 62:1403-16. doi: 10.3233/JAD-170585

51. J.-Park S, Davis RL, Sue CM. Mitochondrial dysfunction in Parkinson's Disease: new mechanistic insights and therapeutic perspectives. Curr Neurol Neurosci Rep. (2018) 18:21. doi: 10.1007/s11910-018-0829-3

52. Kholmukhamedov A, Jobe S. Platelet respiration. Blood Adv. (2019) 3:599. doi: 10.1182/bloodadvances.2018025155

53. Baaten CCFMJ, Moenen FCJI, Henskens YMC, Swieringa F, Wetzels RJH, van Oerle $\mathrm{R}$, et al. Impaired mitochondrial activity explains platelet dysfunction in thrombocytopenic cancer patients undergoing chemotherapy. Haematologica. (2018) 103:1557-67. doi: 10.3324/haematol.2017.185165

54. Menzies RA, Gold PH. The turnover of mitochondria in a variety of tissues of young adult and aged rats. J Biol Chem. (1971) 246:2425-9.

55. Diaz F, Moraes CT. Mitochondrial biogenesis and turnover. Cell Calcium. (2008) 44:24-35. doi: 10.1016/j.ceca.2007.12.004

56. Jobe SM, Wilson KM, Leo L, Raimondi A, Molkentin JD, Lentz SR, et al. Critical role for the mitochondrial permeability transition pore and cyclophilin D in platelet activation and thrombosis. Blood. (2008) 111:1257. doi: 10.1182/blood-2007-05092684

57. Davizon-Castillo P, McMahon B, Aguila S, Bark D, Ashworth K, Allawzi A, et al. TNF-alpha-driven inflammation and mitochondrial dysfunction define the platelet hyperreactivity of aging. Blood. (2019) 134:72740. doi: 10.1182/blood.2019000200

58. Taylor RW, Turnbull DM. Mitochondrial DNA mutations in human disease. Nat Rev. Genet. (2005) 6:389-402. doi: 10.1038/ nrg1606

59. Lodish H, Berk A, Zipursky SL, et al. Molecular Cell Biology. 4th Edn. Section 9.7, Organelle DNAs. New York, NY: W. H. Freeman (2000).

60. Zhang M, Chen JL, Wang PC, Fu CY, Peng H. Complete mitochondrial genome sequence of the human neuroblastoma cell line 751-NA. Genome Announce. (2017) 5:e01185-17. doi: 10.1128/genomeA.01 185-17 
61. Gilkerson R, Bravo L, Garcia I, Gaytan N, Herrera A, Maldonado A, Quintanilla B. The mitochondrial nucleoid: integrating mitochondrial DNA into cellular homeostasis. Cold Spring Harb Persp Biol. (2013) 5:a011080. doi: 10.1101/cshperspect.a011080

62. Moraes CT, Srivastava S, Kirkinezos I, Oca-Cossio J, vanWaveren C, Woischnick M, Diaz F. Mitochondrial DNA structure and function. Int Rev Neurobiol. (2002) 53:3-23. doi: 10.1016/S0074-7742(02)53002-6

63. Holt IJ, Reyes A. Human mitochondrial DNA replication. Cold Spring Harb Perspect Biol. (2012) 4:a012971 doi: 10.1101/cshperspect.a012971

64. Masukata H, Tomizawa J. A mechanism of formation of a persistent hybrid between elongating RNA and template DNA. Cell. (1990) 62:3318. doi: 10.1016/0092-8674(90)90370-T

65. Wanrooij S, Falkenberg M. The human mitochondrial replication fork in health and disease. Biochim Biophys Acta. (2010) 1797:1378-88. doi: 10.1016/j.bbabio.2010.04.015

66. Holt IJ, Lorimer HE, Jacobs HT. Coupled leading- and lagging-strand synthesis of mammalian mitochondrial DNA. Cell. (2000) 100:51524. doi: 10.1016/S0092-8674(00)80688-1

67. Malik AN, Czajka A. Is mitochondrial DNA content a potential biomarker of mitochondrial dysfunction? Mitochondrion. (2013) 13:48192. doi: 10.1016/j.mito.2012.10.011

68. Tin A, Grams ME, Ashar FN, Lane JA, Rosenberg AZ, Grove ML, et al. Association between mitochondrial DNA copy number in peripheral blood and incident CKD in the atherosclerosis risk in communities study. J Am Soc Nephrol. (2016) 27:2467-73. doi: 10.1681/ASN.2015060661

69. Baccarelli AA, Byun HM. Platelet mitochondrial DNA methylation: a potential new marker of cardiovascular disease. Clin Epigenet. (2015) 7:44. doi: 10.1186/s13148-015-0078-0

70. Finsterer J. Genetic, pathogenetic, and phenotypic implications of the mitochondrial A3243G tRNALeu(UUR) mutation. Acta Neurol Scand. (2007) 116:1-14. doi: 10.1111/j.1600-0404.2007.00836.x

71. Pfanner N, Warscheid B, Wiedemann N. Mitochondrial proteins: from biogenesis to functional networks. Nat Rev Mol Cell Biol. (2019) 20:26784. doi: 10.1038/s41580-018-0092-0

72. Dudek J, Rehling P, van der Laan M. Mitochondrial protein import: common principles and physiological networks. Biochim Biophys Acta. (2013) 1833:274-85. doi: 10.1016/j.bbamcr.2012.05.028

73. Neupert W. A perspective on transport of proteins into mitochondria: a myriad of open questions. J Mol Biol. (2015) 427:1135-58. doi: 10.1016/j.jmb.2015.02.001

74. van der Laan M, Meinecke M, Dudek J, Hutu DP, Lind M, Perschil I, et al. Motor-free mitochondrial presequence translocase drives membrane integration of preproteins. Nat Cell Biol. (2007) 9:1152. doi: 10.1038/ ncb1635

75. Alberts B, Johnson A, Lewis J, et al. Molecular Biology of the Cell. 4th Edn. The Transport of Proteins into Mitochondria and Chloroplasts. New York, NY: Garland Science (2002).

76. Kramer PA, Ravi S, Chacko B, Johnson MS, Darley-Usmar VM. A review of the mitochondrial and glycolytic metabolism in human platelets and leukocytes: implications for their use as bioenergetic biomarkers. Redox Biol. (2014) 2:206-10. doi: 10.1016/j.redox.2013.12.026

77. Aibibula M, Naseem KM, Sturmey RG. Glucose metabolism and metabolic flexibility in blood platelets. J Thromb Haemost. (2018) 16:230014. doi: $10.1111 /$ jth. 14274

78. Doery JC G, Hirsh J, Cooper I. Energy metabolism in human platelets:interrelationship between glycolysis and oxidative metabolism. Blood. (1970) 36:159. doi: 10.1182/blood.V36.2.159.159

79. Holmsen H, Setkowsky CA, Day HJ. Effects of antimycin and 2-deoxyglucose on adenine nucleotides in human platelets. Role of metabolic adenosine triphosphate in primary aggregation, secondary aggregation and shape change of platetets. Biochem J. (1974) 144:385-96. doi: 10.1042/bj14 40385

80. Fidler TP, Campbell RA, Funari T, Dunne N, Balderas Angeles E, Middleton EA, Chaudhuri D, Weyrich AS, Abel ED. Deletion of GLUT1 and GLUT3 reveals multiple roles for glucose metabolism in platelet and megakaryocyte function. Cell Rep. (2017) 20:881-94. doi: 10.1016/j.celrep.2017.06.083

81. Clemetson KJ. Platelets and primary haemostasis. Thromb Res. (2012) 129:220-4. doi: 10.1016/j.thromres.2011.11.036
82. Remenyi G, Szasz R, Friese P, Dale George L. Role of mitochondrial permeability transition pore in coated-platelet formation. Arterioscler Thromb Vasc Biol. (2005) 25:46771. doi: 10.1161/01.ATV.0000152726.49229.bf

83. Leytin V, Allen DJ, Mutlu A, Gyulkhandanyan AV, Mykhaylov S, Freedman J. Mitochondrial control of platelet apoptosis: effect of cyclosporin A, an inhibitor of the mitochondrial permeability transition pore. Lab Invest. (2009) 89:374. doi: 10.1038/labinvest.2009.13

84. Lopez JJ, Salido GM E, GÓMez-Arteta, Rosado JA, Pariente JA. Thrombin induces apoptotic events through the generation of reactive oxygen species in human platelets. J Thromb Haemost. (2007) 5:128391. doi: 10.1111/j.1538-7836.2007.02505.x

85. Yamagishi SI, Edelstein D, Du XL, Brownlee M. Hyperglycemia potentiates collagen-induced platelet activation through mitochondrial superoxide overproduction. Diabetes. (2001) 50:1491. doi: 10.2337/diabetes.50.6.1491

86. Choo HJ, Saafir Talib B, Mkumba L, Wagner Mary B, Jobe Shawn M. Mitochondrial calcium and reactive oxygen species regulate agonist-initiated platelet phosphatidylserine exposure. Arterioscler Thromb Vasc Biol. (2012) 32:2946-55. doi: 10.1161/ATVBAHA.112.300433

87. Davì G, Patrono C. Platelet activation and atherothrombosis. N Engl J Med. (2007) 357:2482-94. doi: 10.1056/NEJMra071014

88. Garcia-Souza LF, Oliveira MF. Mitochondria, biological roles in platelet physiology and pathology. Int J Biochem Cell Biol. (2014) 50:15660. doi: 10.1016/j.biocel.2014.02.015

89. Brass LF. $\mathrm{Ca}^{2+}$ homeostasis in unstimulated platelets. J Biol Chem. (1984) 259:12563-70.

90. Figueira TR, Barros MH, Camargo AA, Castilho RF, Ferreira JC B, Kowaltowski AJ, et al. Mitochondria as a source of reactive oxygen and nitrogen species: from molecular mechanisms to human health. Antioxid Redox Sign. (2012) 18:2029-74. doi: 10.1089/ars.2012.4729

91. Lopez JJ, Salido GM, Pariente JA, Rosado JA. Thrombin induces activation and translocation of $\mathrm{Bid}, \mathrm{Bax}$ and $\mathrm{Bak}$ to the mitochondria in human platelets. J Thromb Haemost. (2008) 6:1780-8. doi: 10.1111/j.1538-7836.2008.03111.x

92. Kodama T, Takehara T, Hikita H, Shimizu S, Shigekawa M, Li W, et al. BH3only activator proteins bid and bim are dispensable for bak/bax-dependent thrombocyte apoptosis induced by $\mathrm{Bcl}-\mathrm{xL}$ deficiency: molecular requisites for the mitochondrial pathway to apoptosis in platelets. J Biol Chem. (2011) 286:13905-13. doi: 10.1074/jbc.M110.195370

93. Tang WH, Stitham J, Gleim S, Di Febbo C, Porreca E, Fava C, et al. Glucose and collagen regulate human platelet activity through aldose reductase induction of thromboxane. J Clin Invest. (2011) 121:446276. doi: 10.1172/JCI59291

94. Tang WH, Stitham J, Jin Y, Liu R, Lee SH, Du J, et al. Aldose reductase-mediated phosphorylation of p53 leads to mitochondrial dysfunction, and damage in diabetic platelets. Circulation. (2014) 129:1598-609. doi: 10.1161/CIRCULATIONAHA.113.005224

95. Lee SH, Du J, Stitham J, Atteya G, Lee S, Xiang Y, et al. Inducing mitophagy in diabetic platelets protects against severe oxidative stress. EMBO Mol Med. (2016) 8:779-95. doi: 10.15252/emmm.201506046

96. Gyulkhandanyan AV, Mutlu A, Freedman J, Leytin V. Markers of platelet apoptosis: methodology and applications. J Thromb Thrombolysis. (2012) 33:397-411. doi: 10.1007/s11239-012-0688-8

97. Perrotta PL, Perrotta CL, Snyder EL. Apoptotic activity in stored human platelets. Transfusion. (2003) 43:52635. doi: 10.1046/j.1537-2995.2003.00349.x

98. Kile BT. The role of the intrinsic apoptosis pathway in platelet life and death. J Thromb Haemos. (2009) 7:214-7. doi: 10.1111/j.1538-7836.2009.03366.x

99. Youle RJ, Strasser A. The BCL-2 protein family: opposing activities that mediate cell death. Nat Rev Mol Cell Biol. (2008) 9:47. doi: 10.1038/nrm2308

100. Mason KD, Carpinelli MR, Fletcher JI, Collinge JE, Hilton AA, Ellis S, et al. Programmed anuclear cell death delimits platelet life span. Cell. (2007) 128:1173-86. doi: 10.1016/j.cell.2007.01.037

101. Oltersdorf T, Elmore SW, Shoemaker AR, Armstrong RC, Augeri DJ, Belli $\mathrm{BA}$, et al. An inhibitor of Bcl-2 family proteins induces regression of solid tumours. Nature. (2005) 435:677-81. doi: 10.1038/nature03579

102. Josefsson EC, James C, Henley KJ, Debrincat MA, Rogers KL, Dowling MR, et al. Megakaryocytes possess a functional intrinsic apoptosis pathway that 
must be restrained to survive and produce platelets. J Exp Med. (2011) 208:2017-31. doi: 10.1084/jem.20110750

103. Vandenberg CJ, Josefsson EC, Campbell KJ, James C, Lawlor KE, Kile BT, et al. Loss of Bak enhances lymphocytosis but does not ameliorate thrombocytopaenia in BCL-2 transgenic mice. Cell Death Differ. (2014) 21:676-84. doi: 10.1038/cdd.2013.201

104. Debrincat MA, Pleines I, Lebois M, Lane RM, Holmes ML, Corbin J, et al. BCL-2 is dispensable for thrombopoiesis and platelet survival. Cell Death Dis. (2015) 6:e1721. doi: 10.1038/cddis.2015.97

105. McArthur K, Chappaz S, Kile BT. Apoptosis in megakaryocytes and platelets: the life and death of a lineage. Blood. (2018) 131:605. doi: 10.1182/blood-2017-11-742684

106. Julien O, Wells JA. Caspases and their substrates. Cell Death Differ. (2017) 24:1380. doi: $10.1038 /$ cdd.2017.44

107. Bhatlekar S, Basak I, Edelstein LC, Campbell RA, Lindsey CR, Italiano JE Jr, et al. Anti-apoptotic BCL2L2 increases megakaryocyte proplatelet formation in cultures of human cord blood. Haematologica. (2019) 104:207583. doi: 10.3324/haematol.2018.204685

108. Feng W, Chang C, Luo D, Su H, Yu S, Hua W, et al. Dissection of autophagy in human platelets. Autophagy. (2014) 10:642-51. doi: 10.4161/auto.27832

109. Cao Y, Cai J, Zhang S, Yuan N, Li X, Fang Y, et al. Loss of autophagy leads to failure in megakaryopoiesis, megakaryocyte differentiation, and thrombopoiesis in mice. Exp Hematol. (2015) 43:488-94. doi: 10.1016/j.exphem.2015.01.001

110. Ouseph MM, Huang Y, Banerjee M, Joshi S, MacDonald L, Zhong Y, et al. Autophagy is induced upon platelet activation and is essential for hemostasis and thrombosis. Blood. (2015) 126:1224-33. doi: 10.1182/blood-2014-09-598722

111. Allen GF, Toth R, James J, Ganley IG. Loss of iron triggers PINK1/Parkin-independent mitophagy. EMBO Rep. (2013) 14:1127-35. doi: 10.1038/embor.2013.168

112. Gegg ME, Cooper JM, Chau KY, Rojo M, Schapira AH, Taanman JW. Mitofusin 1 and mitofusin 2 are ubiquitinated in a PINK1/parkin-dependent manner upon induction of mitophagy. Hum Mol Genet. (2010) 19:486170. doi: $10.1093 / \mathrm{hmg} / \mathrm{ddq} 419$

113. Geisler S, Holmstrom KM, Skujat D, Fiesel FC, Rothfuss OC, Kahle PJ, et al. PINK1/Parkin-mediated mitophagy is dependent on VDAC1 and p62/SQSTM1. Nat Cell Biol. (2010) 12:119-31. doi: 10.1038/ncb2012

114. Shiba-Fukushima K, Imai Y, Yoshida S, Ishihama Y, Kanao T, Sato S, et al. PINK1-mediated phosphorylation of the Parkin ubiquitin-like domain primes mitochondrial translocation of Parkin and regulates mitophagy. $S c i$ Rep. (2012) 2:1002. doi: 10.1038/srep01002

115. Wauer T, Simicek M, Schubert A, Komander D. Mechanism of phospho-ubiquitin-induced PARKIN activation. Nature. (2015) 524:370-4. doi: 10.1038/nature14879

116. Choi AM, Ryter SW, Levine B. Autophagy in human health and disease. $N$ Engl J Med. (2013) 368:1845-6. doi: 10.1056/NEJMc1303158

117. Shintani T, Klionsky DJ. Autophagy in health and disease: a double-edged sword. Science. (2004) 306:990-5. doi: 10.1126/science.1099993

118. Kubli DA, Gustafsson AB. Mitochondria and mitophagy: the yin and yang of cell death control. Circ Res. (2012) 111:120821. doi: 10.1161/CIRCRESAHA.112.265819

119. Lee SH, Lee S, Du J, Jain K, Ding M, Kadado AJ, et al. Mitochondrial MsrB2 serves as a switch and transducer for mitophagy. EMBO Mol Med. (2019) 11:e10409. doi: 10.15252/emmm.201910409

120. Koçer A, Yaman A, Niftaliyev E, Dürüyen H, Eryilmaz M, Koçer E. Assessment of platelet indices in patients with neurodegenerative diseases: mean platelet volume was increased in patients with Parkinson's disease. Curr Gerontol Geriatr Res. (2013) 2013:986254. doi: 10.1155/2013/986254

121. Willoughby S, Holmes A, Loscalzo J. Platelets and cardiovascular disease. Euro J Cardiovasc Nurs. (2002) 1:273-88. doi: 10.1016/S1474-51510200038-5

122. Santilli F, Simeone P, Liani R, Davì G. Platelets and diabetes mellitus. Prostaglandins \& Other Lipid Mediat. (2015) 120:2839. doi: 10.1016/j.prostaglandins.2015.05.002

123. Dewitte A, Lepreux S, Villeneuve J, Rigothier C, Combe C, Ouattara A, et al. Blood platelets and sepsis pathophysiology: A new therapeutic prospect in critically [corrected] ill patients? Ann Intens Care. (2017) 7:115. doi: 10.1186/s13613-017-0337-7
124. Lannan KL, Phipps RP, White RJ. Thrombosis, platelets, microparticles and PAH: more than a clot. Drug Discov Today. (2014) 19:12305. doi: 10.1016/j.drudis.2014.04.001

125. Sinauridze EI, Kireev DA, Popenko NY, Pichugin AV, Panteleev MA, Krymskaya OV, et al. Platelet microparticle membranes have 50- to 100fold higher specific procoagulant activity than activated platelets. Thromb Haemost. (2007) 97:425-34. doi: 10.1160/TH06-06-0313

126. Gawaz M, Vogel S. Platelets in tissue repair: control of apoptosis and interactions with regenerative cells. Blood. (2013) 122:2550. doi: 10.1182/blood-2013-05-468694

127. Song S, Pursell ZF, Copeland WC, Longley MJ, Kunkel TA, Mathews CK. DNA precursor asymmetries in mammalian tissue mitochondria and possible contribution to mutagenesis through reduced replication fidelity. Proc Natl Acad Sci USA. (2005) 102:4990. doi: 10.1073/pnas.0500253102

128. Chial H, Craig J. mtDNA and mitochondrial diseases. Nat Educ. (2008) 1:217.

129. Ryzhkova AI, Sazonova MA, Sinyov VV, Galitsyna EV, Chicheva MM, Melnichenko AA, et al. Mitochondrial diseases caused by mtDNA mutations: a mini-review. Therap Clin Risk Manag. (2018) 14:193342. doi: 10.2147/TCRM.S154863

130. Shokolenko IN, Wilson GL, Alexeyev MF. Aging: a mitochondrial DNA perspective, critical analysis and an update. World J Exp Med. (2014) 4:4657. doi: 10.5493/wjem.v4.i4.46

131. Ito S, Ohta S, Nishimaki K, Kagawa Y, Soma R, Kuno SY, et al. Functional integrity of mitochondrial genomes in human platelets and autopsied brain tissues from elderly patients with Alzheimer's disease. Proc Natl Acad Sci USA. (1999) 96:2099-103. doi: 10.1073/pnas.96.5.2099

132. Hurtado-Roca Y, Ledesma M, Gonzalez-Lazaro M, Moreno-Loshuertos R, Fernandez-Silva P, Enriquez JA, et al. Adjusting MtDNA quantification in whole blood for peripheral blood platelet and leukocyte counts. PLOS ONE. (2016) 11:e0163770. doi: 10.1371/journal.pone.0163770

133. Lindqvist D, Wolkowitz OM, Picard M, Ohlsson L, Bersani FS, Fernstrom J, et al. Circulating cell-free mitochondrial DNA, but not leukocyte mitochondrial DNA copy number, is elevated in major depressive disorder. Neuropsychopharmacology. (2018) 43:1557-64. doi: 10.1038/s41386-017-0001-9

134. Chait A, Bornfeldt KE. Diabetes and atherosclerosis: is there a role for hyperglycemia? J Lipid Res. (2009) 50(Suppl):S3359. doi: 10.1194/jlr.R800059-JLR200

135. Madamanchi Nageswara R, Runge Marschall S. Mitochondrial dysfunction in atherosclerosis. Circ Res. (2007) 100:46073. doi: 10.1161/01.RES.0000258450.44413.96

136. Lindemann S, KrÄMer B, Seizer P, Gawaz M. Platelets, inflammation and atherosclerosis. J Thromb Haemost. (2007) 5:203-11. doi: 10.1111/j.1538-7836.2007.02517.x

137. Cybulsky MI, Iiyama K, Li H, Zhu S, Chen M, Iiyama M, et al. A major role for VCAM-1, but not ICAM-1, in early atherosclerosis. J Clin Invest. (2001) 107:1255-62. doi: 10.1172/JCI11871

138. Ran J, Guo X, Li Q, Mei G, Lao G. Platelets of type 2 diabetic patients are characterized by high ATP content and low mitochondrial membrane potential. Platelets. (2009) 20:588-93. doi: 10.3109/09537100903288422

139. Zharikov S, Shiva S. Platelet mitochondrial function: from regulation of thrombosis to biomarker of disease. Biochem Soc Trans. (2013) 41:118. doi: 10.1042/BST20120327

140. Schneider DJ. Factors contributing to increased platelet reactivity in people with diabetes. Diab Care. (2009) 32:525-7. doi: 10.2337/dc08-1865

141. Tang WH, Martin KA, Hwa J. Aldose reductase, oxidative stress, and diabetic mellitus. Front Pharmacol. (2012) 3:87. doi: 10.3389/fphar.2012. 00087

142. Xin G, Wei Z, Ji C, Zheng H, Gu J, Ma L, et al. Metformin uniquely prevents thrombosis by inhibiting platelet activation and mtDNA release. Sci Rep. (2016) 6:36222. doi: 10.1038/srep36222

143. Semple JW, Italiano JE, Freedman J. Platelets and the immune continuum. Nat Rev Immunol. (2011) 11:264. doi: 10.1038/nri2956

144. Hottz ED, Bozza FA, Bozza PT. Platelets in immune response to virus and immunopathology of viral infections. Front Med. (2018) 5:121. doi: 10.3389/fmed.2018.00121

145. Ali RA, Wuescher LM, Worth RG. Platelets: essential components of the immune system. Curr Trends Immunol. (2015) 16:65-78. 
146. Morrell CN, Aggrey AA, Chapman LM, Modjeski KL. Emerging roles for platelets as immune and inflammatory cells. Blood. (2014) 123:2759. doi: 10.1182/blood-2013-11-462432

147. Protti A, Fortunato F, Caspani ML, Pluderi M, Lucchini V, Grimoldi $\mathrm{N}$, et al. Mitochondrial changes in platelets are not related to those in skeletal muscle during human septic shock. PLoS ONE. (2014) 9:e96205 doi: 10.1371/journal.pone.0096205

148. Singer M. The role of mitochondrial dysfunction in sepsis-induced multiorgan failure. Virulence. (2014) 5:66-72. doi: 10.4161/viru.26907

149. Sharma B, Sharma M, Majumder M, Steier W, Sangal A, Kalawar M. Thrombocytopenia in septic shock patients-a prospective observational study of incidence, risk factors and correlation with clinical outcome. Anaes Intens Care. (2007) 35:833-1018. doi: 10.1177/0310057X0703500604

150. Claushuis TAM, van Vught LA, Scicluna BP, Wiewel MA, Klein Klouwenberg PMC, Hoogendijk AJ, et al. Thrombocytopenia is associated with a dysregulated host response in critically ill sepsis patients. Blood. (2016) 127:3062. doi: 10.1182/blood-2015-11-680744

151. Boudreau LH, Duchez AC, Cloutier N, Soulet D, Martin N, Bollinger J, et al. Platelets release mitochondria serving as substrate for bactericidal group IIA-secreted phospholipase A2 to promote inflammation. Blood. (2014) 124:2173-83. doi: 10.1182/blood-2014-05-573543

152. Andersson SG, Zomorodipour A, Andersson JO, Sicheritz-Ponten T, Alsmark UC, Podowski RM, et al. The genome sequence of Rickettsia prowazekii and the origin of mitochondria. Nature. (1998) 396:13340. doi: 10.1038/24094

153. Veitinger M, Varga B, Guterres SB, Zellner M. Platelets, a reliable source for peripheral Alzheimer's disease biomarkers? Acta Neuropathol Commun. (2014) 2:65. doi: 10.1186/2051-5960-2-65

154. Krige D, Carroll MT, Cooper JM, Marsden CD, Schapira AHV. Platelet mitochondria function in Parkinson's disease. Ann Neurol. (1992) 32:7828. doi: 10.1002/ana.410320612

155. Catricala S, Torti M, Ricevuti G. Alzheimer disease and platelets: how's that relevant. Immun Ageing. (2012) 9:20. doi: 10.1186/1742-4933-9-20

156. Talib LL, Joaquim HP, Forlenza OV. Platelet biomarkers in Alzheimer's disease. World J Psychiatry. (2012) 2:95-101. doi: 10.5498/wjp.v2.i6.95

157. Behari M, Shrivastava $M$. Role of platelets in neurodegenerative diseases: a universal pathophysiology. Int J Neurosci. (2013) 123:287-99. doi: 10.3109/00207454.2012.751534

158. Bush AI, Martins RN, Rumble B, Moir R, Fuller S, Milward E, et al. The amyloid precursor protein of Alzheimer's disease is released by human platelets. J Biol Chem. (1990) 265:15977-83.

159. Valla J, Berndt JD, Gonzalez-Lima F. Energy hypometabolism in posterior cingulate cortex of Alzheimer's patients: superficial laminar cytochrome oxidase associated with disease duration. J Neurosci. (2001) 21:492330. doi: 10.1523/JNEUROSCI.21-13-04923.2001

160. Swerdlow RH, Parks JK, Cassarino DS, Maguire DJ, Maguire RS, Bennett JP, et al. Cybrids in Alzheimer's disease: a cellular model of the disease? Neurology. (1997) 49:918. doi: 10.1212/WNL.49.4.918

161. Winklhofer KF, Haass C. Mitochondrial dysfunction in Parkinson's disease. Biochim Biophys Acta. (2010) 1802:29-44. doi: 10.1016/j.bbadis.2009.08.013
162. Benecke R, Strümper P, Weiss H. Electron transfer complexes I and IV of platelets are abnormal in Parkinson's disease but normal in Parkinsonplus syndromes. Brain. (1993) 116:1451-63. doi: 10.1093/brain/116. 6.1451

163. Haas RH, Nasirian F, Nakano K, Ward D, Pay M, Hill R, et al. Low platelet mitochondrial complex I and complex II/III activity in early untreated parkinson's disease. Ann Neurol. (1995) 37:71422. doi: 10.1002/ana.410370604

164. Shults CW. Therapeutic role of coenzyme Q10 in Parkinson's disease. Pharmacol Therap. (2005) 107:12030. doi: 10.1016/j.pharmthera.2005.02.002

165. Kingsbury AE, David Mardsen C, Foster OJF. DNA fragmentation in human substantia nigra: Apoptosis or perimortem effect? Mov Disord. (1998) 13:877-84. doi: 10.1002/mds.870130604

166. Andersen JK. Does neuronal loss in Parkinson's disease involve programmed cell death? BioEssays. (2001) 23:640-6. doi: 10.1002/bies.1089

167. Bortolato M, Chen K, Shih JC. Monoamine oxidase inactivation: from pathophysiology to therapeutics. Adv Drug Deliv Rev. (2008) 60:152733. doi: 10.1016/j.addr.2008.06.002

168. Nagatsu T, Sawada M. Molecular mechanism of the relation of monoamine oxidase $\mathrm{B}$ and its inhibitors to Parkinson's disease: possible implications of glial cells. J Neural Transm. (2006) 71:53-65 doi: 10.1007/978-3-211-33328-0_7

169. Dias V, Junn E, Mouradian MM. The role of oxidative stress in Parkinson's disease. J Parkinsons Dis. (2013) 3:461-91. doi: 10.3233/JPD130230

170. Adolfsson R, Gottfries CG, Oreland L, Wiberg Å, Winblad B. Increased activity of brain and platelet monoamine oxidase in dementia of Alzheimer type. Life Sci. (1980) 27:1029-34. doi: 10.1016/0024-3205(80)90025-9

171. Cesura AM, Pletscher A. The new generation of monoamine oxidase inhibitors. In: Mitsuhashi S, Kojima T, Nakanishi N, Fujimoto T, Goto O, Miyusaki S, et al. editors. Progress in Drug Research/Fortschritte der Arzneimittelforschung/Progrès des recherches pharmaceutiques. Basel: Birkhäuser Basel (1992). p. 171-297.

172. Fuentes E, Araya-Maturana R, Urra FA. Regulation of mitochondrial function as a promising target in platelet activation-related diseases. Free Radic Biol Med. (2019) 136:172182. doi: 10.1016/j.freeradbiomed.2019.01.007

Conflict of Interest: The authors declare that the research was conducted in the absence of any commercial or financial relationships that could be construed as a potential conflict of interest.

Copyright (C) 2019 Melchinger, Jain, Tyagi and Hwa. This is an open-access article distributed under the terms of the Creative Commons Attribution License (CC BY). The use, distribution or reproduction in other forums is permitted, provided the original author(s) and the copyright owner(s) are credited and that the original publication in this journal is cited, in accordance with accepted academic practice. No use, distribution or reproduction is permitted which does not comply with these terms. 